\title{
Atrial fibrillation in diabetes: A cause for concern?*
}

\author{
Benjamin R. Szwejkowski ${ }^{1 \#}$, Sushma Rekhraj ${ }^{1}$, Andrew D. Morris ${ }^{2}$, Allan D. Struthers ${ }^{1}$ \\ ${ }^{1}$ Centre for Cardiovascular and Lung Biology, University of Dundee, Ninewells Hospital and Medical School, Dundee, UK; \\ ${ }^{\#}$ Corresponding Author: b.szwejkowski@dunde.ac.uk \\ ${ }^{2}$ Biomedical Research Institute, University of Dundee, Ninewells Hospital and Medical School, Dundee, UK
}

Received 13 July 2012; revised 16 August 2012; accepted 26 August 2012

\begin{abstract}
Atrial fibrillation (AF) is one of the most common cardiac arrhythmias and is associated with significant morbidity and mortality. It is becoming increasingly evident diabetes is a significant risk factor for the development of AF. The reason for this link is not clearly understood, however it is clear that other co-morbid diseases associated with diabetes such as hypertension and obesity may be implicated or there may be direct arrthymogenic affects of glucose dysregulation on the myocardium. The development of $A F$ in patients with diabetes may be an ominous sign given the increased risk of death from cardiovascular disease and we propose this is an under researched area where treatments may bring benefits over and above those patients without diabetes in terms of morbidity or death from cardiovascular disease.
\end{abstract}

Keywords: Diabetes; Atrial Fibrillation; Mechanisms; Treatment

\section{INTRODUCTION: ATRIAL FIBRILLATION IN DIABETES, AN UNMET NEED}

Atrial fibrillation (AF) is one of the most common cardiac arrhythmias, with a lifetime risk of developing atrial fibrillation in both men and women of one in four [1]. There is also a substantial cost to the associated morbidity and mortality; in the UK, Stewart et al. (2004) estimated that the direct cost of AF to the NHS in 2000 was $£ 459$ million i.e. $0.97 \%$ of total NHS expenditure [2]. Hospitalisations account for about $50 \%$ of this cost and drug prescriptions about $20 \%$ [2]. AF has a significant impact on mortality. Framingham data suggest that $\mathrm{AF}$ is associated with a 1.5 to 1.9 fold increase in mortality after adjustment for pre-existing cardiovascular conditions [3]. AF particularly increases the long term risk of stroke and heart failure [4].

"Declaration of competing interests: nothing to declare.
Why is AF important in patients with diabetes? It is becoming increasingly recognised that in addition to traditional risk factors for $\mathrm{AF}$, such as hypertension, ischaemic heart disease and heart failure, diabetes is also a risk factor for AF. The exact pathophysiology for this observation is unclear but is important because diabetes may mask the cardiac symptoms associated with the onset of $\mathrm{AF}$ and this masking of symptoms is a potential mechanism for the increased risk of stroke in patients with diabetes, i.e. if $\mathrm{AF}$ is under diagnosed then anti-coagulation will be delayed or not considered. The development of AF in patients with diabetes has also been shown to increase the risk of stroke [5]. Stroke risk is most commonly measured by the well validated "CHADS2" score whereby diabetes scores one point, giving an adjusted stroke rate of $2.8 \%$ per year with a $95 \%$ confidence interval of $2.0-3.8[6,7]$.

The increasing incidence of both AF and diabetes, and the association between the two conditions, highlights a potentially important unmet need and under researched cause of morbidity and mortality in patients with diabetes. In many ways, this may be comparable to the increased risk of ischaemic heart disease in patients with diabetes. This review focuses on three main areas; the epidemiology and outcome of AF in patients with diabetes, the potential mechanisms for the increased incidence of $\mathrm{AF}$ in patients with diabetes and to discuss the evidence of benefit in treating $\mathrm{AF}$ in patients with diabetes.

\section{THE EPIDEMIOLOGY OF ATRIAL FIBRILLATION IN DIABETES}

Diabetes mellitus has been shown in numerous epidemiological studies to be a risk factor for the development of AF. One large study, Wilhelmsen et al. (2001), did not find a correlation between $\mathrm{AF}$ and diabetes [8], but subsequent larger studies have shown significant correlations and these are summarised in Table 1.

In an analysis of all 845,748 in-patient records from all the Veterans Health Administrations hospitals in America, Movahed et al. (2005) reported a significant correlation between diabetes and AF [9]. AF occurred in 
Table 1. Comparison of the association of AF with diabetes from the major published studies expressed as odds and hazard ratios.

\begin{tabular}{|c|c|c|c|c|c|c|c|c|}
\hline Author & $\begin{array}{c}\text { Total } \\
\text { number of } \\
\text { patients }\end{array}$ & $\begin{array}{l}\text { Prevalence } \\
\text { of AF in } \\
\text { diabetes }\end{array}$ & $\begin{array}{c}\text { Prevalence } \\
\text { of AF in non } \\
\text { diabetes }\end{array}$ & Odds ratio & $\begin{array}{c}95 \% \\
\text { confidence } \\
\text { interval }\end{array}$ & $\begin{array}{c}\text { Hazard } \\
\text { ratio }\end{array}$ & $\begin{array}{c}95 \% \\
\text { confidence } \\
\text { interval }\end{array}$ & $p$ value \\
\hline $\begin{array}{l}\text { Movahed et al. } \\
\quad \text { (2005) }\end{array}$ & 845,748 & & & 2.13 & $2.10-2.16$ & & & $<0.05$ \\
\hline $\begin{array}{l}\text { Ostgren et al. } \\
\quad \text { (2004) }\end{array}$ & 1739 & 4 & 2 & 2 & $0.9-4.7$ & & & $<0.05$ \\
\hline $\begin{array}{l}\text { Nichols et al. } \\
\quad \text { (2009) }\end{array}$ & 17,372 & 3.6 & 2.5 & & & 1.26 & $1.08-1.46$ & $<0.05$ \\
\hline $\begin{array}{l}\text { Benjamin et al. } \\
\text { (1994) }\end{array}$ & 4731 & & & $\begin{array}{c}1.4 \text { (men) } \\
1.6 \text { (women) }\end{array}$ & & & & $<0.05$ \\
\hline $\begin{array}{l}\text { Aksnes et al. } \\
\quad(2008)\end{array}$ & 15,245 & & & & & 1.49 & $1.14-1.94$ & $<0.05$ \\
\hline $\begin{array}{l}\text { Psaty et al. } \\
\text { (1997) }\end{array}$ & 5201 & & & 1.08 & $1.03-1.13$ & & & $<0.05$ \\
\hline
\end{tabular}

$14.9 \%$ of patients with diabetes compared with $10.3 \%$ in the control group of patients with hypertension but no diabetes. Atrial flutter occurred in $4 \%$ of patients with diabetes compared with $2.5 \%$ in the control group. When congestive heart failure, coronary heart disease and left ventricular hypertrophy were accounted for, diabetes still remained a strong independent risk factor for $\mathrm{AF}$ and atrial flutter, with odds ratios of 2.13 and 2.20 respectively. This study is by far the largest study looking at the correlation between diabetes and AF. There are a number of drawbacks in that this study was retrospective and was conducted in hospitalised patients only.

The two other larger studies, Nichols et al. (2009) and Aksnes et al. (2008) reported similar findings from large diabetes registries [10,11]. Nichols et al. (2009) found after adjustment for other risk factors, diabetes was associated with a $26 \%$ increased risk of AF among women, but intriguingly diabetes was not a predictor among men. The Framingham Heart Study, Östgren et al. (2004) and Psaty et al. (1997) looked at smaller numbers of patients but found similar significant correlations [12-14]. Aksnes et al. (2008) studied large numbers of patients in the VALUE trial to see who developed AF [11]. Of the patients who developed AF during the follow up period, patients with diabetes had a significantly higher chance of developing AF which was also more persistent.

We should also consider dysglycaemia in AF patients. Johansen et al. (2008) looked to see if 75 year old patients with AF had undiagnosed dysglycaemia using an oral glucose tolerance test [15]. Their numbers were small but showed the prevalence of undiagnosed dysglycaemia was higher if AF had been present for more than five years. Although there are obvious limitations to this study, it does seem diabetes is a true culprit in producing chronic AF.

\section{POSSIBLE MECHANISMS WHEREBY DIABETES MAY CAUSE ATRIAL FIBRILLATION}

There are no studies that look at the pathogenesis of why diabetes might trigger AF, but two potential mechanisms have been postulated. The first explanation is that the relationship is confounded by other conditions associated with diabetes itself. The second possibility is that pathophysiological mechanisms associated with diabetes and hyperglycaemia directly cause AF.

In support of the first hypothesis, diabetes is inextricably linked to coronary artery disease, hypertension and obesity, all of which are also causal factors for AF in their own right [16]. Therefore it may be that AF is indirectly linked to diabetes through its associations with these factors. In support of this Östgren et al. (2004), found the combination of diabetes and hypertension to produce AF more than diabetes did in isolation [13]. Obesity and hypertension are also strongly associated with left atrial dilatation, which in turn is a strong risk factor for AF. Stritzke et al. (2009) studied the association of obesity and hypertension to left atrial volume [16]. Patients were followed up prospectively over 10 years. After adjustment for age and sex, the odds ratio for the effect of obesity associated left atrial enlargement was 2.7 while hypertension was less (1.1). It would therefore seem obesity is a greater determinant of left atrial enlargement than hypertension. Therefore co-morbid obesity associated with diabetes is one possible reason for the association of diabetes with AF.

The second hypothesis to consider is potential direct effects of dysglycaemia on the atrium. The possible mechanisms are poorly understood, although it is clear that impaired glucose metabolism may cause electrical instability of the myocardium. Wasada et al. (1995) re- 
ported four cases of patients with type 2 diabetes with sick sinus syndrome and hyper-insulinaemia [17]. They proposed the potential mechanism to be that insulin stimulates the cell membrane $\mathrm{Na}^{+} / \mathrm{K}^{+}$ATPase, arguing that hyper-insulinaemia is characteristic of early stages of pre-clinical diabetes when insulin resistance predominates. This stimulation of the receptor may lead to chronic hyper-stimulation of the receptor and thus arrhythmias. Studies have also shown intra-operative hyperglycaemia during cardiac surgery is associated with a higher incidence of AF [18], and that insulin and potassium infusions decrease complications including AF [19].

Rutter et al. (2003) investigated the impact of insulin resistance on heart structure and function in a community based sample of Framingham study patients [20]. Interestingly, hyperglycaemia correlated more closely with left ventricular mass in women than men. These changes could be accounted for by obesity. Importantly, they found that the more severe glucose intolerance, the greater the left atrial size in both men and women. Lind et al. also found a correlation between diabetes and left atrial size [21]. Overall it appears that insulin resistance probably acts on the myocardium to cause left ventricular hypertrophy and increased atrial size which then leads to AF. This study confirms findings from other previous studies, which have all shown a correlation between left ventricular mass and insulin resistance [22-26].

The potential mechanisms by which insulin resistance is associated with left ventricular hypertrophy has been reviewed by Young et al. (2002) [27]. An overview of the potential mechanisms are elegantly summarised in Figure 1, by Rutter et al. (2003). A detailed discussion of the cellular mechanisms for the development of cardiomyopathies is beyond the scope of this review. In summary however, glucotoxicity has been implicated in the generation of reactive oxygen species and insulin resistance and may thereby also affect cardiac gene expression [27]. Fatty acids appear to do the same [27]. Following on from this, glucose and fatty acids seem to be central to altered metabolic adaptation in response to pressure overload as well as the fact that glucose leads to transcriptional alterations of a number of genes [27]. The end result of these transcriptional alterations is induction of foetal genes and substrate switching, enabling the heart to maintain cardiac output. It should be noted that in hearts without pressure overload there is also switching to foetal gene expression, possibly in a response to glucose [27]. The concept of metabolic maladaptation, as discussed by Young et al. (2002) encompasses three main concepts, as summarised in Figure 2. These are lipotoxicity, glucotoxicity and glucolipotoxicity [27]. Lipotoxicity is the theory whereby a hyperlipid environment results in accumulation of lipids within the heart. This excess accumulation of lipids can cause reactive oxygen species, and apoptosis resulting in contractile dysfunction [27]. Glucotoxicity is similar to lipotoxicity in that chronic hyperglycaemia leads to reactive oxygen species formation. It also appears that in hypertrophied hearts and hearts of patients with diabetes there is insulin resistance as a result of chronic hyperglycaemia [27]. Finally, glucolipotoxicity is the combination of these two processes, possibly accelerated by the suggestion that hyperglycaemia down regulates the expression of fatty acid metabolising genes, therefore accelerating the deposition of lipids and accelerating cardiac dysfunction [27].

A small number of case reports have linked hypoglycaemia with AF [28-30]. This is perhaps not too surpriseing since hypoglycaemia increases catecholamines which are arrythmogenic. Lip et al. (2005) postulated fluctuating glucose levels may be the cause of AF, as opposed to chronic hypoglycaemia [31]. Interestingly, not only has hypoglycaemia been reported with atrial fibrillation but in the early 1990's, Pollock et al. (1996) reported three cases from the Emergency Department where hypoglycaemia presented as profound bradycardia [32]. The administration of glucose in all three cases resulted in the normalisation of sinus rhythm. Perhaps this link between hypoglycaemia and $\mathrm{AF}$ is due to prolongation of the QT interval. The syndrome known as "dead in bed" was described in the 1990's in type 1 diabetic patients who have nocturnal hypoglycaemia that prolongs the QT interval causing ventricular tachycardias [33]. Hypoglycaemia is also associated with raised plasma catecholamine levels and low potassium, which may unmask or increase the effect hypoglycaemia on QT prolongation [34,35].

\section{HOW EFFECTIVE ARE THE DRUGS USED TO TREAT ATRIAL FIBRILLATION?}

It is already well known that patients with diabetes and $\mathrm{AF}$ are at an increased risk of stroke, and this risk is recognised explicitly when assessing whether to use anticoagulation. The relative risk for stroke in a person with diabetes is 1.7 [36]. This compares with relative risks of 1.6 if there is a history of hypertension, 1.4 if there is a history of heart failure or 2.5 if there is a history of a previous stroke or TIA. [36]. Therefore patients with diabetes usually need careful consideration for stroke thromboprophylaxis if they develop AF. However, to date, no major clinical trials looking at treatments or outcomes in AF have published sub-group analysis specifically looking at outcomes in patients with diabetes. It is therefore unknown if patients with diabetes with $\mathrm{AF}$ fare worse than patients without diabetes with $\mathrm{AF}$, or whether they respond differently to treatment.

There are some potential reasons as to why people with diabetes may benefit more than the general population 


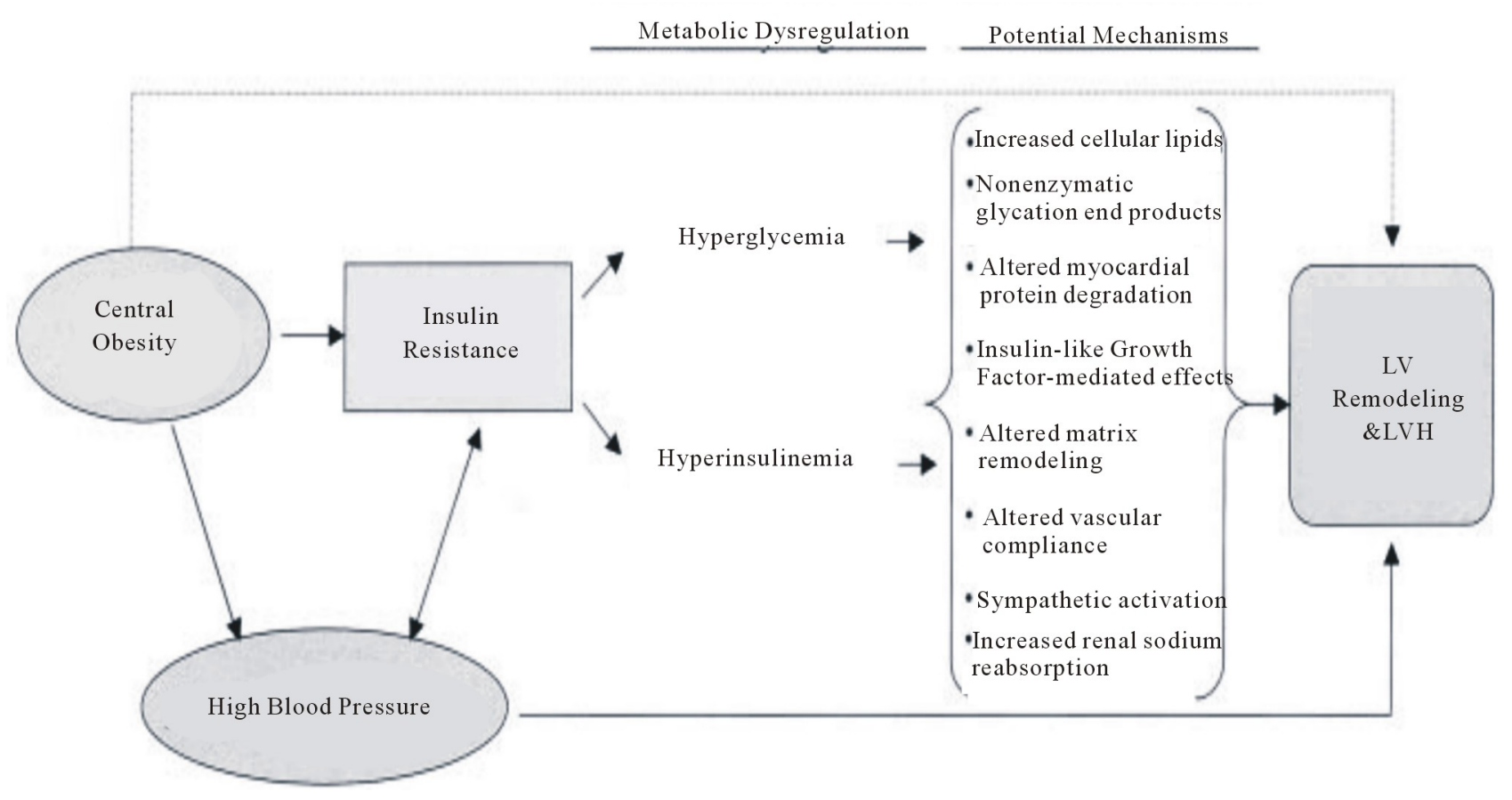

Figure 1. Potential mechanisms by which insulin resistance are associated with left ventricular hypertrophy, reproduced from Rutter, M.K., Parise, H., Benjamin, E.J., Levy, D., Larson, M.G., Meigs, J.B., et al. (2003) Impact of glucose intolerance and insulin resistance on cardiac structure and function: Sex-related differences in the Framingham heart study. Circulation, 107, 448-454 [20].

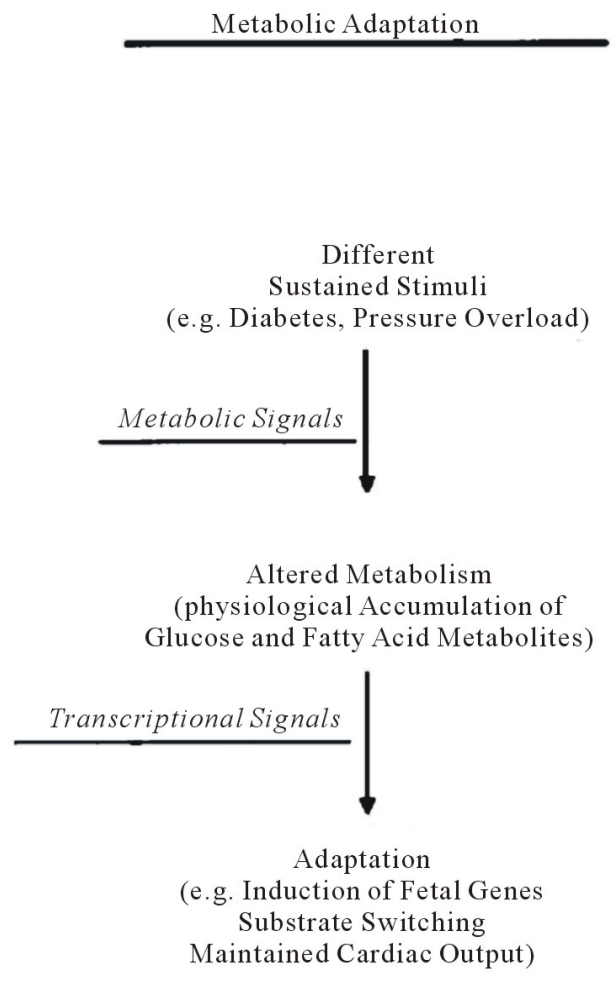

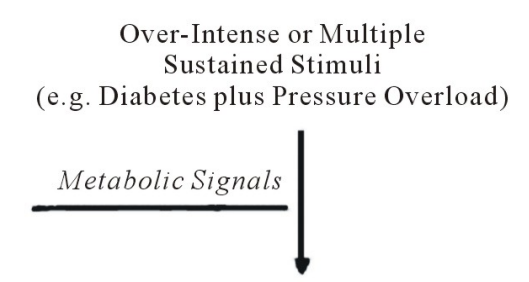

Altered Metabolism (PathologicalAccumulation of Glucose and Fatty Acid Metabolites)

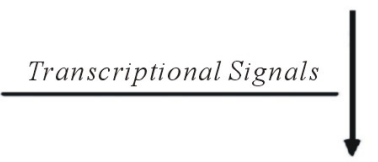

Maladaptation (e.g. Initiation of Apoptosis Chronic Activation of PKCs Blockage of Substrate Switching Reactive Oxygen Species Generation Contractile Dysfunction)

Figure 2. Summary of the possible mechanisms for metabolic adaptation and maladaptation of the heart, reproduced from Young, M.E., McNulty, P. and Taegtmeyer, H. (2002) Adaptation and maladaptation of the heart in diabetes: Part II: Potential mechanisms. Circulation, 105, 1861-1870 [27]. 
from current $\mathrm{AF}$ therapies. It is well known patients with type 2 diabetes are at an increased risk of cardiovascular disease which accounts for $70 \%$ of total mortality in diabetes [37]. In type 2 diabetes, insulin resistance results in impaired glucose metabolism along with increased likelihood of hypertension, central obesity, endothelial dysfunction, abnormal lipid profiles and pro-thrombotic factors $[38,39]$. Unfortunately in Type 2 diabetes not only is the incidence of these cardiovascular risk factors more common, but type 2 diabetes is a major cardiovascular risk factor in its own right [40]. There is a two to four fold risk of developing coronary heart disease, stroke and peripheral vascular disease in patients with type 2 diabetes compared to patients without diabetes [37,38]. Patients with diabetes are more likely to develop multivessel coronary artery disease which puts them at even greater risk of plaque ulceration and thrombosis [41]. Similar differences have been described in peripheral blood vessels [41]. The mortality after cardiac events (including sudden death) are also significantly increased compared to patients without diabetes $[38,42]$. Further more, despite death from cardiovascular disease falling over the last 35 years, there has not been a decline in cardiovascular deaths in patients with type 2 diabetes [38]. Could the development of AF in these settings of increased cardiovascular risk be an even more ominous sign in patients with diabetes such that they need more aggressive treatment or even different treatment than non-diabetic patients? These questions have not yet been answered and more research is needed.

This leads to the question of what can be done to either prevent $\mathrm{AF}$ or improve the outcome of $\mathrm{AF}$ in patients with diabetes over and above standard rate or rhythm control. In the first instance by way of background we must review the two biggest studies of this topic. The HOT study showed that patients with diabetes have the most to gain from intensive blood pressure control when compared to other patient groups [43]. Reducing blood pressure to $\leq 80 \mathrm{mmHg}$ produced a $51 \%$ reduction in major cardiovascular events compared with $\leq 90$ $\mathrm{mmHg}$. By contrast, in the ACCORD study ( $\mathrm{n}=4733$ ), there was no benefit in reducing systolic blood pressure $\leq 120 \mathrm{mmHg}$ compared with $\leq 140 \mathrm{mmHg}$ in terms of reducing fatal and non-fatal cardiovascular events in people with diabetes [44]. There is no obvious explanation for these contrasting results, except possibly that contemporary treatments (e.g. with statins) was very different in the HOT study era from the current ACCORD study era.

Nevertheless LVH is a determinant of left atrial size and remodelling, and it would be expected that aggressive blood pressure control should prevent AF occurring in patients with diabetes. Angiotensin converting enzyme inhibitors (ACE inhibitors) do seem to prevent $\mathrm{AF}$ in hypertension supporting this hypothesis. A large cohort study, L'Allier et al. (2004), of eight million people on a database showed a reduced incidence of $\mathrm{AF}$ in patients on ACE inhibitors with hypertension [45]. By contrast the GISSI-AF study found that the angiotensin receptor blocker (ARB's) valsartan did not reduce the incidence of AF in patients who before recruitment had two or more documented episodes of AF [46]. The important point here is that GISSI-AF recruited patients who had already had episodes of AF whereas in the L'Allier et al. (2004) study, the use of ACE inhibitors was restricted to patients with no previous history of AF. Interestingly in GISSI-AF, there was a reduced incidence of AF in the patients with diabetes subgroup but this was not significant $(\mathrm{p}=0.11)$.

It is more conclusive that angiotensin converting enzyme inhibitors (ACE inhibitors) and angiotensin receptor blocker (ARB's) reduce the incidence of new onset $\mathrm{AF}$ in heart failure. Heart failure is linked to diabetes due to the reasons discussed previously. There are three main meta-analysis published in this area [47-49]. A metaanalysis by Kalus et al. (2006) of four clinical trials reports resulting effect of renin angiotensin system blockade in reducing new onset AF [47]. All four studies included patients with left ventricular dysfunction and showed a reduction in new onset $\mathrm{AF}$ in patients treated with ACE inhibitors or ARB's. Anand et al. (2006) analysed nine randomised control trials and found that the use of ACE inhibitors and ARB's across the trials showed a $18 \%$ risk reduction in the onset of new $\mathrm{AF}$, but most importantly there was a $43 \%$ risk reduction in the subset of patients with heart failure [48]. Jibrini et al. (2008) included 11 randomised trials and included patients with heart failure, myocardial infarction and hypertension [49]. They found that treatment with ACE inhibitors or ARB's reduced the relative risk for the development of new onset $\mathrm{AF}$ by $23 \%$ in hypertension, $11 \%$ in post myocardial infarction patients and by $32 \%$ in heart failure patients. These three meta-analyses of the major trials are the most compelling evidence for the use of ACE inhibitors and ARB's to prevent new onset AF in patients with impaired left ventricular function. None of these trials published sub-group analysis of patients with diabetes.

A final discussion point is the use of thiazolidinediones. A case report from Greece has described two patients with type 2 diabetes who had an improvement in paroxysmal AF with rosiglitazone [50]. There is some evidence that thiazolidinediones reduce $\mathrm{C}$ reactive protein levels and inhibit oxidative stress [51,52]. It could be that thiazolidinediones with their pleitropic properties affect atrial remodelling [50]. However, thiazolidinediones are controversial in their links to heart failure and ischaemic heart disease, which may limit their po- 
tential use to prevent AF.

\section{SUMMARY}

$\mathrm{AF}$ is one of the most common cardiac arrhythmias, and seems to be more common amongst people with diabetes. AF has a significant impact on morbidity and mortality, and in particular increases the long term risk of stroke. The reasons for AF being more common in patients with diabetes remain unclear. The specific combination of $\mathrm{AF}$ and diabetes is an under researched area that needs further research. Thiazolidinediones may prevent $\mathrm{AF}$ but at this stage the evidence for this is limited to theory and case reports. ACE inhibitors and ARB's have shown promise in preventing new onset AF especially in patients with heart failure. Although the evidence for ACE inhibitors and ARBs preventing AF in diabetes is sparse, it is reasonable to presume they do so, although many patients with diabetes will have alternative indications for them anyway e.g. hypertension or microalbuminuria. Our review article highlights the need for more research into AF prevention and treatment in diabetes.

\section{REFERENCES}

[1] Lloyd-Jones, D.M., Wang, T.J., Leip, E.P., Larson, M.G., Levy, D., Vasan, R.S., et al. (2004) Lifetime risk for development of atrial fibrillation: The Framingham heart study. Circulation, 110, 1042-1046.

doi:10.1161/01.CIR.0000140263.20897.42

[2] Stewart, S., Murphy, N.F., Walker, A., McGuire, A. and McMurray, J.J. (2004) Cost of an emerging epidemic: An economic analysis of atrial fibrillation in the UK. Heart, 90, 286-292. doi:10.1136/hrt.2002.008748

[3] Benjamin, E., Wolf, P., D’Agostino, R., Silbershatz, H., Kannel, W. and Levy, D. (1998) Impact of atrial fibrillation on the risk of death: The Framingham heart study. Circulation, 98, 946-952. doi:10.1161/01.CIR.98.10.946

[4] Stewart, S., Hart, C.L., Hole, D.J. and McMurray, J.J. (2002) A population-based study of the long-term risks associated with atrial fibrillation: 20-year follow-up of the Renfrew/Paisley study. American Journal of Medicine, 113, 359-364. doi:10.1016/S0002-9343(02)01236-6

[5] Sugishita, K., Shiono, E., Sugiyama, T. and Ashida, T. (2003) Diabetes influences the cardiac symptoms related to atrial fibrillation. Circulation Journal, 67, 835-888. doi:10.1253/circj.67.835

[6] Gage, B.F., van Walraven, C., Pearce, L., Hart, R.G., Koudstaal, P.J., Boode, B.S.P., et al. (2004) Selecting patients with atrial fibrillation for anticoagulation: Stroke risk stratification in patients taking aspirin. Circulation, 110, 2287-2292.

[7] Gage, B.F., Waterman, A.D., Shannon, W., Boechler, M., Rich, M.W. and Radford, M.J. (2001) Validation of clinical classification schemes for predicting stroke: Results from the national registry of atrial fibrillation. Journal of the American Medicine Association, 285, 2864-2870.

[8] Wilhelmsen, L., Rosengren, A. and Lappas, G. (2001) Hospitalizations for atrial fibrillation in the general male population: Morbidity and risk factors. Journal of Internal Medicine, 250, 382-389.

doi:10.1046/j.1365-2796.2001.00902.x

[9] Movahed, M., Hashemzadeh, M. and Jamal, M. (2005) Diabetes mellitus is a strong, independent risk for atrial fibrillation and flutter in addition to other cardiovascular disease. International Journal of Cardiology, 105, 315321. doi:10.1016/j.ijcard.2005.02.050

[10] Nichols, G.A., Reinier, K. and Chugh, S.S. (2009) Independent contribution of diabetes to increased prevalence and incidence of atrial fibrillation. Diabetes Care, 32, 18511856. doi:10.2337/dc09-0939

[11] Aksnes, T., Schmieder, R., Kjeldsen, S., Ghani, S., Hua, T. and Julius, S. (2008) Impact of new-onset diabetes mellitus on development of atrial fibrillation and heart failure in high-risk hypertension (from the value trial). American Journal of Cardiology, 101, 634-638. doi:10.1016/j.amjcard.2007.10.025

[12] Benjamin, E.J, Wolf, P.A., D’Agostino, R.B., Silbershatz, H., Kannel, W.B. and Levy, D. (1998) Impact of atrial fibrillation on the risk of death: The Framingham heart study. Circulation, 98, 946-952.

[13] Ostgren, C.J., Merlo, J., Rastam, L. and Lindblad, U. (2004) Atrial fibrillation and its association with type 2 diabetes and hypertension in a Swedish community. Diabetes, Obesity and Metabolism, 6, 367-374. doi:10.1111/j.1462-8902.2004.00358.x

[14] Psaty, B.M., Manolio, T.A., Kuller, L.H., Kronmal, R.A, Cushman, M., Fried, L.P., et al. (1997) Incidence of and risk factors for atrial fibrillation in older adults. Circulation, 96, 2455-2461. doi:10.1161/01.CIR.96.7.2455

[15] Johansen, O., Brustad, E., Enger, S. and Tveit, A. (2008) Prevalence of abnormal glucose metabolism in atrial fibrillation: A case control study in 75-year old subjects. Cardiovascular Diabetology, 7, 28. doi:10.1186/1475-2840-7-28

[16] Stritzke, J., Markus, M.R.P., Duderstadt, S., Lieb, W., Luchner, A., Döring, A., et al. (2009) The aging process of the heart: Obesity is the main risk factor for left atrial enlargement during aging: The MONICA/KORA (monitoring of trends and determinations in cardiovascular disease/cooperative research in the region of Augsburg) study. Journal of the American College of Cardiology, 54, 1982-1989. doi:10.1016/j.jacc.2009.07.034

[17] Wasada, T., Katsumori, K., Hasumi, S., Kasanuki, H., Arii, H., Saeki, A., et al. (1995) Association of sick sinus syndrome with hyperinsulinemia and insulin resistance in patients with non-insulin-dependent diabetes mellitus: Report of four cases. Internal Medicine, 34, 1174-1177. doi:10.2169/internalmedicine.34.1174

[18] Gandhi, G., Nuttall, G., Abel, M., Mullany, C., Schaff, H., Williams, B., et al. (2005) Intraoperative hyperglycemia and perioperative outcomes in cardiac surgery patients. Mayo Clinic Proceedings, 80, 862-866.

doi:10.4065/80.7.862 
[19] Lazar, H.L., Chipkin, S.R., Fitzgerald, C.A., Bao, Y., Cabral, H. and Apstein, C.S. (2004) Tight glycemic control in diabetic coronary artery bypass graft patients improves perioperative outcomes and decreases recurrent ischemic events. Circulation, 109, 1497-502. doi:10.1161/01.CIR.0000121747.71054.79

[20] Rutter, M.K., Parise, H., Benjamin, E.J., Levy, D., Larson, M.G., Meigs, J.B., et al. (2003) Impact of glucose intolerance and insulin resistance on cardiac structure and function: Sex-related differences in the Framingham heart study. Circulation, 107, 448-454.

[21] Lind, L., Berne, C., Andren, B. and Lithell, H. (1996) Relationship between diastolic hypertension and myocardial morphology and function in elderly males with diabetes mellitus. Diabetologia, 39, 1603-1606. doi: $10.1007 / \mathrm{s} 001250050621$

[22] Sundstrom, J., Lind, L., Nystrom, N., Zethelius, B., Andren, B., Hales, C.N., et al. (2000) Left Ventricular concentric remodeling rather than left ventricular hypertrophy is related to the insulin resistance syndrome in elderly men. Circulation, 101, 2595-2600.

[23] Palmieri, V., Bella, J.N., Arnett, D.K., Liu, J.E., Oberman, A., Schuck, M.-Y., et al. (2001) Effect of type 2 diabetes mellitus on left ventricular geometry and systolic function in hypertensive subjects: Hypertension genetic epidemiology network (HyperGEN) Study. Circulation, 103, 102-107.

[24] Galvan, A.Q., Galetta, F., Natali, A., Muscelli, E., Sironi, A.M., Cini, G., et al. (2000) Insulin resistance and hyperinsulinemia: No independent relation to left ventricular mass in humans. Circulation, 102, 2233-2238.

[25] Uusitupa, M., Siitonen, O., Pyorala, K., Mustonen, J., Voutilainen, E., Hersio, K., et al. (1987) Relationship of blood pressure and left ventricular mass to serum insulin levels in newly diagnosed non-insulin-dependent (type 2) diabetic patients and in non-diabetic subjects. Diabetes Research, 4, 19-25.

[26] Verdecchia, P., Reboldi, G., Schillaci, G., Borgioni, C., Ciucci, A., Telera, M.P., et al. (1999) Circulating insulin and insulin growth factor-1 are independent determinants of left ventricular mass and geometry in essential hypertension. Circulation, 100, 1802-1807.

[27] Young, M.E., McNulty, P. and Taegtmeyer, H. (2002) Adaptation and Maladaptation of the heart in diabetes: part II: Potential mechanisms. Circulation, 105, 18611870.

[28] Collier, A., Matthews, D.M., Young, R.J. and Clarke, B.F. (1987) Transient atrial fibrillation precipitated by hypoglycaemia: Two case reports. Postgraduate Medical Journal, 63, 895-897. doi:10.1136/pgmj.63.744.895

[29] Odeh, M., Oliven, A. and Bassan, H. (1990) Transient atrial fibrillation precipitated by hypoglycemia. Annals of Emergency Medicine, 19, 565-567. doi:10.1016/S0196-0644(05)82191-2

[30] Baxter, M.A., Garewal, C., Jordan, R., Wright, A.D. and Nattrass, M. (1990) Hypoglycaemia and atrial fibrillation. Postgraduate Medical Journal, 66, 981. doi:10.1136/pgmj.66.781.981

[31] Lip, G.Y. and Varughese, G.I. (2005) Diabetes mellitus and atrial fibrillation: Perspectives on epidemiological and pathophysiological links. International Journal of Cardiology 105, 319-321. doi:10.1016/j.ijcard.2005.03.003

[32] Pollock, G., Brady, W.J., Jr., Hargarten, S., DeSilvey, D. and Carner, C.T. (1996) Hypoglycemia manifested by sinus bradycardia: A report of three cases. Academic Emergency Medicine, 3, 700-707. doi:10.1111/j.1553-2712.1996.tb03495.x

[33] Gill, G.V., Woodward, A., Casson, I.F. and Weston, P.J. (2009) Cardiac arrhythmia and nocturnal hypoglycaemia in type 1 diabetes - The "dead in bed" syndrome revisited. Diabetologia, 52, 42-45. doi:10.1007/s00125-008-1177-7

[34] Marques, J.L., George, E., Peacey, S.R., Harris, N.D., Macdonald, I.A., Cochrane, T., et al. (1997) Altered ventricular repolarization during hypoglycaemia in patients with diabetes. Diabetic Medicine, 14, 648-654. doi:10.1002/(SICI)1096-9136(199708)14:8<648::AID-DI A418>3.0.CO;2-1

[35] Robinson, R.T., Harris, N.D., Ireland, R.H., Macdonald, I.A. and Heller, S.R. (2004) Changes in cardiac repolarization during clinical episodes of nocturnal hypoglycaemia in adults with Type 1 diabetes. Diabetologia, 47, 312-315. doi:10.1007/s00125-003-1292-4

[36] (1994) Risk factors for stroke and efficacy of antithrombotic therapy in atrial fibrillation. Analysis of pooled data from five randomized controlled trials. Archives of Internal Medicine, 154, 1449-1157. doi:10.1001/archinte.1994.00420130036007

[37] Laakso, M. (1999) Hyperglycemia and cardiovascular disease in type 2 diabetes. Diabetes, 48, 937-942.

[38] Jaffar, A.R. and Assad, M. (2003) Current concepts of cardiovascular diseases in diabetes mellitus. International Journal of Cardiology, 89, 123-134. doi:10.1016/S0167-5273(02)00510-7

[39] Nesto, R.W. (2004) Correlation between cardiovascular disease and diabetes mellitus: Current concepts. American Journal of Medicine, 116, 11S-22S.

[40] Kannel, W.B. (1985) Lipids, diabetes, and coronary heart disease: Insights from the Framingham study. American Heart Journal, 110, 1100-1107. doi:10.1016/0002-8703(85)90224-8

[41] Milicevic, Z., Raz, I., Beattie, S.D., Campaigne, B.N., Sarwat, S., Gromniak, E., et al. (2008) Natural history of cardiovascular disease in patients with diabetes: Role of hyperglycemia. Diabetes Care, 31, S155-S160.

[42] Goraya, T.Y., Leibson, C.L., Palumbo, P.J., Weston, S.A., Killian, J.M., Pfeifer, E.A., et al. (2002) Coronary atherosclerosis in diabetes mellitus: A population-based autopsy study. Journal of the American College of Cardiology, 40, 946-953. doi:10.1016/S0735-1097(02)02065-X

[43] Hansson, L., Zanchetti, A., Carruthers S.G., Dahlof, B., Elmfeldt, D., Julius, S., et al. (1998) Effects of intensive blood-pressure lowering and low-dose aspirin in patients with hypertension: Principal results of the Hypertension Optimal Treatment (HOT) randomised trial. HOT Study Group. Lancet, 351, 1755-1762. doi:10.1016/S0140-6736(98)04311-6 
[44] Cushman, W.C., Evans, G.W., Byington, R.P., Goff, D.C., Jr., Grimm, R.H., Jr., Cutler, J.A., et al. (1575) Effects of intensive blood-pressure control in type 2 diabetes mellitus. The New England Journal of Medicine, 362, 15751585.

[45] L'Allier, P.L., Ducharme, A., Keller, P.F., Yu, H., Guertin, M.C. and Tardif, J.C. (2004) Angiotensin-converting enzyme inhibition in hypertensive patients is associated with a reduction in the occurrence of atrial fibrillation. Journal of the American College of Cardiology, 44, 159164. doi:10.1016/j.jacc.2004.03.056

[46] Disertori, M., Latini, R., Barlera, S., Franzosi, M.G., Staszewsky, L., Maggioni, A.P., et al. (2009) Valsartan for prevention of recurrent atrial fibrillation. The New England Journal of Medicine, 360, 1606-1617. doi:10.1056/NEJMoa0805710

[47] Kalus, J.S., Coleman, C.I. and White, C.M. (2006) The impact of suppressing the renin-angiotensin system on atrial fibrillation. The Journal of Clinical Pharmacology, 46, 21-28. doi: $10.1177 / 0091270005283284$

[48] Anand, K., Mooss, A.N., Hee, T.T. and Mohiuddin, S.M. (2006) Meta-analysis: Inhibition of renin-angiotensin system

\section{ABBREVIATIONS}

$\mathrm{AF}$

Atrial fibrillation;

ACCORD Action to Control Cardiovascular Risk in Diabetes trial;

ACE

Angiotensin converting enzyme;

ARB

prevents new-onset atrial fibrillation. American Heart Journal, 152, 217-222. doi:10.1016/j.ahj.2006.01.007

[49] Jibrini, M.B., Molnar, J. and Arora, R.R. (2008) Prevention of atrial fibrillation by way of abrogation of the renin-angiotensin system: A systematic review and metaanalysis. The American Journal of Therapeutics, 15, 3643. doi:10.1097/MJT.0b013e31804beb59

[50] Korantzopoulos, P., Kokkoris, S., Kountouris, E., Protopsaltis, I., Siogas, K. and Melidonis, A. (2008) Regression of paroxysmal atrial fibrillation associated with thiazolidinedione therapy. International Journal of Cardiology, 125, e51-e53. doi:10.1016/j.ijcard.2006.12.063

[51] Qayyum, R. and Adomaityte, J. (2006) Meta-analysis of the effect of thiazolidinediones on serum C-reactive protein levels. American Journal of Cardiology, 97, 655-658. doi:10.1016/j.amjcard.2005.09.105

[52] Da Ros, R., Assaloni, R. and Ceriello, A. (2004) The preventive anti-oxidant action of thiazolidinediones: A new therapeutic prospect in diabetes and insulin resistance. Diabetic Medicine, 21, 1249-1252. doi:10.1111/j.1464-5491.2004.01312.x

TIA

HOT

GISSI-AF
Transient ischaemic attack; Hypertension Optimal Treatment trial; Gruppo Italiano per lo Studio della Sopravvivenza nell'Infarto Miocardico-Atrial Fibrillation trial. 